\title{
Bacteriological Profile and Antibiogram of Gram Positive Nosocomial Isolates from Intensive Care Units with Special Reference to Methicillin Resistant Staphylococcus aureus (MRSA) in a Tertiary Care Hospital of North Karnataka, India
}

\author{
Zarrin Afroz $^{1 *}$, Basavaraj C. Metri ${ }^{2}$, Faisal Nasim Gilani ${ }^{3}$ and P. Jyothi ${ }^{4}$ \\ ${ }^{1}$ Department of Microbiology, G.S Medical College and Hospital, Pilkhuwa - 245304 District \\ - Hapur, Uttar Pradesh, India \\ ${ }^{2}$ Department of Microbiology, ${ }^{4}$ Department of Forensic Medicine, Shri B.M. Patil Medical \\ College and Research Centre, BLDE University, Vijayapura - 586103, India \\ ${ }^{3}$ Department of Forensic Medicine, G.S. Medical College and Hospital, Pilkhuwa- 245304, \\ Hapur, India \\ *Corresponding author
}

\section{Keywords}

Nosocomial infection, Gram positive bacteria, MRSA, Antibiotic susceptibility pattern

Article Info

Accepted:

24 September 2018 Available Online: 10 October 2018

\section{A B S T R A C T}

Nosocomial infection is a key factor in determining clinical outcomes among patients admitted in intensive care units. Studies on nosocomial infections in ICUs found that respiratory tract infections, blood stream infections, urinary tract infections and soft tissue infections are the common nosocomial infections in ICUs. These organisms causing nosocomial infections are highly resistant to antibiotics. Early recognition of bacteria and appropriate antimicrobial therapy are essential for controlling infection, preventing the morbidity and improve the quality of life. Aims of this study are to find out the profile of Gram positive bacteria causing nosocomial infection in patients admitted in intensive care units and to know the antibiotic susceptibility pattern of the nosocomial isolates. A total of 192 culture positive samples were taken from various clinical specimens. The organisms were identified by Gram staining, cultural characteristics and a battery of biochemical tests. Drug susceptibility was performed on the isolates by Kirby Bauer's disk diffusion method. A total of 202 organisms were isolated from 192 various clinical samples. Respiratory tract infection 76(39.6\%) was the most common infection in Intensive care units. The number of Gram positive isolates was 60 (29.7\%). 142 (70.3\%) Gram negative organisms were isolated. The most common Gram positive cocci was Staphylococcus aureus 34 (16.8\%) followed by CONS 16(26.6\%). Among Gram positive cocci minimum resistance was seen against vancomycin $(6.7 \%)$ followed by linezolid $(10 \%)$ and cotrimoxazole $(26.6 \%)$. Methicillin resistance was seen in $28(82.35 \%)$ of $S$. aureus. $57.1 \%$ of MRSA caused respiratory tract infection. This study shows that Gram positive bacteria can cause serious infections in intensive care units. The most common isolates were $S$. aureus followed by CONS the isolates were resistant to most of the drugs. For Gram positive cocci the most effective antibiotics were vancomycin followed by linezolid and cotrimoxazole. Appropriate antibiotic utilization in Intensive Care Units is crucial not only in ensuring an optimal outcome but also in preventing multidrug resistant bacteria. 


\section{Introduction}

An infection is considered as HealthcareAssociated Infection (HAI) or nosocomial infection if it occurs within 48 hours after hospitalization, or after 3 days of discharge or 30 days after operation. According to $\mathrm{CDC}$ (Centre for disease prevention and control) guidelines The National Nosocomial Surveillance System (NNIS) states that nosocomial infection results from an adverse reaction to the presence of an infectious agent or toxin that was not presenting or incubating at the time of admission to the hospital.

Recently CDC guidelines states that the date of event of the NHSN (National healthcare safety network) site-specific infection criterion occurs on or after the 3rd calendar day of admission to an inpatient location where day of admission is calendar day 1 (CDC, 2016; Al-Jawady et al., 2012).

Nosocomial infection is an important factor in determining clinical outcomes among patients admitted in intensive care units. Critically ill patients in intensive care unit (ICU) are 5-10 times more likely to acquire nosocomial infections than those in general wards (Datta et al., 2014; Kaul et al., 2007).

Studies on nosocomial infections in ICUs have found that respiratory tract infections, blood stream infections, urinary tract infections and soft tissue infections are the common nosocomial infections in ICUs.

Samples of urine, blood, pus, sputum and endotracheal secretions when evaluated had Gram negative isolates followed by Gram positive isolates. Among the Gram positive bacterial organisms isolated from ICUs there is a high prevalence of Staphylococcus aureus and Coagulase negative Staphylococcus species followed by Enterococcus (Robert, 1998; Sharma et al., 2013).
These Gram positive organisms isolated are highly resistant to antibiotics. Most of them are methicillin resistant Staphylococcus aureus, high level aminoglycoside producing Enterococci and vancomycin resistant Enterococci Previous studies have shown that for Gram positive organisms isolated from ICUs the most effective drug has been vancomycin and has proved as a reliable agent for empirical treatment (Sheth et al., 2012).

The consequences depend on the source involved, organisms associated, underlying morbidity and appropriateness of interventions received.

This may be related to the use of large number of invasive monitoring devices, endotracheal and tracheostomy tubes, factors like extremes of age, immunocompromised status, malnutrition, severe underlying disease, wide use of antibiotics and high incidence of cross infection (Datta et al., 2014).

The incidence and prevalence of multidrug resistant organisms are so high in the hospital settings that even effective drugs like fluoroquinolones, third generation cephalosporins, aminoglycosides etc. are fast losing their utility in covering hospital pathogens, thus restricting the choice of antimicrobials for treating serious infections.

Early recognition of bacteria and appropriate antimicrobial therapy are essential for preventing the morbidity, improve the quality of life and decrease the spread of resistance. Since limited data are available concerning infection, mortality rates and antibiotic susceptibility of nosocomial Gram positive pathogens in our hospital settings, therefore the present study was taken to determine the types, frequency of Gram positive nosocomial bacterial isolates and their antibiotic susceptibility pattern. 


\section{Materials and Methods}

The present study was undertaken at the department of Microbiology, BLDEUs Shri B.M. Patil medical college and hospital, Vijayapur during the period from 01-01-2014 to 30-06-2015. The study included a total of 192 culture positive samples taken from patients of both sexes irrespective of age groups admitted in the ICUs of BLDEUs, Shri B.M. Patil medical college, hospital and research centre, Vijayapur.

\section{Inclusion criteria}

Samples collected after 48 hours of admission of the patient to neonatal ICU (NICU), surgical ICU (SICU), pediatric ICU (PICU), Intensive cardiac care unit (ICCU) and critical care unit (CCU) were included. Single or mixed growth from patients was included in the study.

\section{Exclusion criteria}

Anaerobic, fungal organisms, repeat samples from the same patient and samples collected before 48 hours of admission of the patient to ICU were excluded.

Blood samples were collected under aseptic precautions in blood culture bottles. Urine specimens from catheterised patients were collected in universal containers. Respiratory samples like sputum and endotracheal aspirates were collected in sqat, wide mouth disposable containers. Throat Swabs were placed in swab transport system containing stuart's transport medium and sent to lab. Pus from superficial wound were collected with swab and from deep wounds it was aspirated and collected in sterile small screw capped bottles. The containers were labelled with the name of patient, identification number, culture site, date of collection and time of collection. The specimens were transported to the laboratory within 30 minutes to 2 hours the samples were inoculated on Nutrient agar, Blood agar and Mac Conkey's medium for samples other than urine. Urine samples were inoculated on CLED agar and Mac Conkey's medium. The media were incubated at $37^{\circ} \mathrm{C}$ for 24-48 hours. The isolates were identified by Gram staining, colony morphology and standard biochemical tests (Collee and Marr, 2012).

Antibiotic susceptibility tests were done on Gram positive isolates by Kirby bauer disc diffusion method according to CLSI guidelines (CLSI, 2012) The discs used were penicillin $(10 \mu \mathrm{g}) \quad$ cloxacillin $(10 \mu \mathrm{g})$, ciprofloxacin $(5 \mu \mathrm{g})$, cefuroxime $(30 \mu \mathrm{g})$, ceftriaxone $(30 \mu \mathrm{g})$, cephalexin $(30 \mu \mathrm{g})$, azithromycin $(15 \mu \mathrm{g})$, gentamicin $(10 \mu \mathrm{g})$, tetracycline $(30 \mu \mathrm{g})$, linezolid $(30 \mu \mathrm{g})$, vancomycin $(30 \mu \mathrm{g})$, norfloxacin $(10 \mu \mathrm{g})$, piperacillin-tazobactam $(100 / 10 \mu \mathrm{g}) \quad$ and cotrimoxazole $(25 \mu \mathrm{g})$. Methicillin resistant Staphylococcus (MRSA) was detected by standard disc diffusion method using cefoxitin $(30 \mu \mathrm{g})$ and oxacillin $(1 \mu \mathrm{g})$ discs The organisms were deemed methicillin resistant when zone of inhibition was $<10 \mathrm{~mm}$ for oxacillin and $<19 \mathrm{~mm}$ for cefoxitin discs (Cekovska et al., 2005).

\section{Statistical analysis}

It was carried out by SPSS 14 software and data was analysed

In the form of percentage with tables

By diagrammatic presentation in the form of pie charts and graphs

\section{Results and Discussion}

A total of 202 organisms were isolated from 192 various clinical samples. Most of the 
isolates were from respiratory specimens [sputum 38, endotracheal secretion 32 and throat swab 6] 76 (39.5\%) followed by pus samples $44(22.9 \%)$. The distribution of various clinical samples is shown in Table 1.

Most of the samples obtained were from males $116(60.6 \%)$ and $76(39.6 \%)$ were from females. The major age group was 1 day - 1 year which included 40 (20.9\%) samples followed by 41- 50 years and 61-70 years which included $26(13.5 \%)$ samples. The demographic characteristics of the study are shown in Figure 1.

Respiratory tract infection $76(39.6 \%)$ was the most common infection in Intensive care units. It was followed by skin and soft tissue infection 44 (22.9\%), urinary tract infection 40 (20.8\%) and blood stream infection 32 $(16.7 \%)$. The distribution of nosocomial infections is shown in Figure 2.

Out of the 192 patients suffering from nosocomial infections $82 \quad(42.7 \%)$ were suffering from comorbid conditions like hypertension, diabetes, COPD and AIDS.

Majority of them were suffering from hypertension $36(18.7 \%)$ followed by Diabetes $20(10.4 \%) .110(57.3 \%)$ of patients were not suffering from any comorbid condition (Table 2).

Out of the 192 samples processed 202 organisms were isolated. From 182 samples single organism was isolated. 10 samples had mixed growth. The number of Gram positive isolates was $60(29.7 \%)$ and 142 (70.3\%) Gram negative organisms were isolated.

The most common Gram positive cocci was Staphylococcus aureus 34 (56.6\%) followed by Coagulase negative Staphylococci 16 (26.6\%). The distribution of Gram positive organisms is shown in (Table 3).
The most common nosocomial infection caused by Staphylococcus aureus was respiratory tract infections $16(47.1 \%) .12$ $(75 \%)$ of CONS caused blood stream infections.4 (40\%) of Enterococcus species was the major cause of urinary tract infection and skin and soft tissue infection (Table 4).

Staphylococcus aureus was the most common Gram positive isolate in CCU, ICCU, NICU and SICU. The distribution of isolates in different ICUs is shown in Table 5.

\section{Antibiotic resistance pattern of Gram positive cocci}

Among Gram positive organisms maximum resistance was seen against penicillin and norfloxacin $(96.6 \%)$ followed by cephalexin (93.3\%) and ceftriaxone, ciprofloxacin (83.3\%). Minumum resistance was seen against vancomycin $(6.7 \%)$ followed by linezolid (10\%) and cotrimoxazole (26.6\%).

All of the Staphylococcus aureus were seen to be resistant against penicillin (100\%). It was followed by resistance to cephalexin and norfloxacin $(94.1 \%)$.

High resistance was also seen against cloxacillin and ceftriaxone (82.3\%), ciprofloxacin and cefuroxime $(76.5 \%)$ and, azithromycin and gentamicin (58.8\%).

Maximum susceptibility of Staphylococcus was seen against vancomycin (100\%) followed by linezolid (94.1\%), cotrimoxazole $(88.2 \%)$ and tetracycline $(70.6 \%)$.

Among CONS maximum resistance was seen against fluoroquinolones like ciprofloxacin and norfloxacin $(100 \%)$ followed by penicillin (87.5\%) and cephalosporins. Most of them were found to be susceptible to vancomycin (100\%) followed by linezolid (87.5\%), cotrimoxazole and tetracycline (62.5\%). 
Most of the Enterococcus species were found to be resistant to penicillin, cloxacillin, cephalosporins, azithromicin, gentamicin and norfloxacin $(100 \%)$ followed by tetracycline, piperacillin - tazobactam (80\%) and cotrimoxazole (60\%). Maximum susceptibility was seen against linezolid (80\%) followed by vancomycin $(60 \%)$. The antibiotic resistance pattern is of Gram positive organisms are shown in (Fig. 3).

Distribution of methicillin resistant Staphylococcus aureus (MRSA)

Of the 34 Staphylococcus aureus isolates methicillin resistance was seen in 28 $(82.35 \%) .57 .1 \%$ of MRSA caused respiratory tract infection. $21.4 \%$ of MRSA were responsible for blood stream infection and skin and soft tissue infection (Fig. 4).
Patients in the intensive care units (ICUs) have a 5 to 7 fold higher risk of nosocomial infections.20-25\% of the nosocomial infections develop in ICUs. By far the most important causative agents of nosocomial infections are bacteria. A large number of Gram positive bacteria like $S$. aureus, CONS and Enterococcus are potential pathogens in hospitalised patients which can lead to respiratory tract infections, urinary tract infections, skin and soft tissue infections and blood stream infections (Sharma et al., 2013).

Antibiotic resistance in the intensive care units (ICUs) is a major world-wide problem. It has been found that the spread of drug resistant organisms in the ICUs is related to the widespread use of antibiotics (Radji et al., 2011).

Table.1 Distribution of various clinical samples received from different ICU

\begin{tabular}{|l|l|l|}
\hline Specimen & No & Percentage (\%) \\
\hline Respiratory specimens & $\mathbf{7 6}$ & $\mathbf{3 9 . 5 \%}$ \\
\hline 1. Sputum 38(19.8\%) & & \\
\hline 2. ET secretion 32(16.7\%) & & \\
\hline 3. Throat swab 06(3.1\%) & & \\
\hline Pus & $\mathbf{4 4}$ & $\mathbf{2 2 . 9 \%}$ \\
\hline Urine & $\mathbf{4 0}$ & $\mathbf{2 0 . 8} \%$ \\
\hline Blood & $\mathbf{3 2}$ & $\mathbf{1 6 . 7 \%}$ \\
\hline Total & $\mathbf{1 9 2}$ & $\mathbf{1 0 0 \%}$ \\
\hline
\end{tabular}

Table.2 Comorbid conditions

\begin{tabular}{|l|c|c|}
\hline Co-morbid condition & Number & Percentage \\
\hline 1.Hypertension & 36 & $18.7 \%$ \\
\hline 2.Diabeties & 20 & $10.4 \%$ \\
\hline 3.Hypertension \& Diabetes & 16 & $8.8 \%$ \\
\hline 4.COPD & 6 & $3.1 \%$ \\
\hline 5.AIDS & 4 & $2.1 \%$ \\
\hline No co-morbid condition & 110 & $57.3 \%$ \\
\hline Total & $\mathbf{1 9 2}$ & $\mathbf{1 0 0 \%}$ \\
\hline
\end{tabular}


Table.3 Bacteriological profile of Gram positive organisms isolated from ICUs

\begin{tabular}{|l|l|l|}
\hline Organisms & No & Percentage (\%) \\
\hline 1. Staphylococcus aureus & 34 & $56.6 \%$ \\
\hline 2. CONS & 16 & $26.6 \%$ \\
\hline 3. Enterococcus species & 10 & $16.6 \%$ \\
\hline Total & $\mathbf{6 0}$ & $\mathbf{1 0 0 \%}$ \\
\hline
\end{tabular}

Table.4 Distribution of each pathogen in different nosocomial infections

\begin{tabular}{|l|l|l|l|l|c|}
\hline Organism & $\begin{array}{l}\text { RTI } \\
\text { No }(\%)\end{array}$ & $\begin{array}{l}\text { SSTI } \\
\text { No }(\%)\end{array}$ & $\begin{array}{l}\text { UTI } \\
\text { No }(\%)\end{array}$ & $\begin{array}{l}\text { BSI } \\
\text { No }(\%)\end{array}$ & $\begin{array}{c}\text { Total } \\
\text { No }\end{array}$ \\
\hline Staphylococcus aureus & $16(47.1 \%)$ & $10(29.4 \%)$ & $00(0 \%)$ & $08(23.5 \%)$ & $\mathbf{3 4}$ \\
\hline CONS & $02(12.5 \%)$ & $02(12.5 \%)$ & $00(0 \%)$ & $12(75 \%)$ & $\mathbf{1 6}$ \\
\hline Enterococcus species & $00(0 \%)$ & $04(40 \%)$ & $04(40 \%)$ & $02(20 \%)$ & $\mathbf{1 0}$ \\
\hline Total organisms & 18 & 16 & 04 & 22 & $\mathbf{6 0}$ \\
\hline
\end{tabular}

Table.5 Distribution of the isolates in different ICUs

\begin{tabular}{|l|l|l|l|l|l|}
\hline Organism & $\begin{array}{l}\text { CCU } \\
\text { No }(\%)\end{array}$ & $\begin{array}{l}\text { ICCU } \\
\text { No }(\%)\end{array}$ & $\begin{array}{l}\text { NICU } \\
\text { No }(\%)\end{array}$ & $\begin{array}{l}\text { SICU } \\
\text { No }(\%)\end{array}$ & $\begin{array}{l}\text { PICU } \\
\text { No (\%) }\end{array}$ \\
\hline Staphylococcus aureus (34) & $8(66.6 \%)$ & $10(71.4 \%)$ & $12(50 \%)$ & $4(50 \%)$ & $0(0 \%)$ \\
\hline CONS (16) & $2(16.6 \%)$ & $0(0 \%)$ & $10(41.6 \%)$ & $2(25 \%)$ & $2(100 \%)$ \\
\hline Enterococcus species (10) & $2(16.6 \%)$ & $4(28.5 \%)$ & $2(8.3 \%)$ & $2(25 \%)$ & $0(0 \%)$ \\
\hline Total (60) & $\mathbf{1 2 ( 1 0 0 \% )}$ & $\mathbf{1 4}(\mathbf{1 0 0 \% )})$ & $\mathbf{2 4}(\mathbf{1 0 0 \% )}$ & $\mathbf{8 ( 1 0 0 \% )}$ & $\mathbf{2 ( 1 0 0 \% )}$ \\
\hline
\end{tabular}

Fig.1 Demographic characteristics of the study

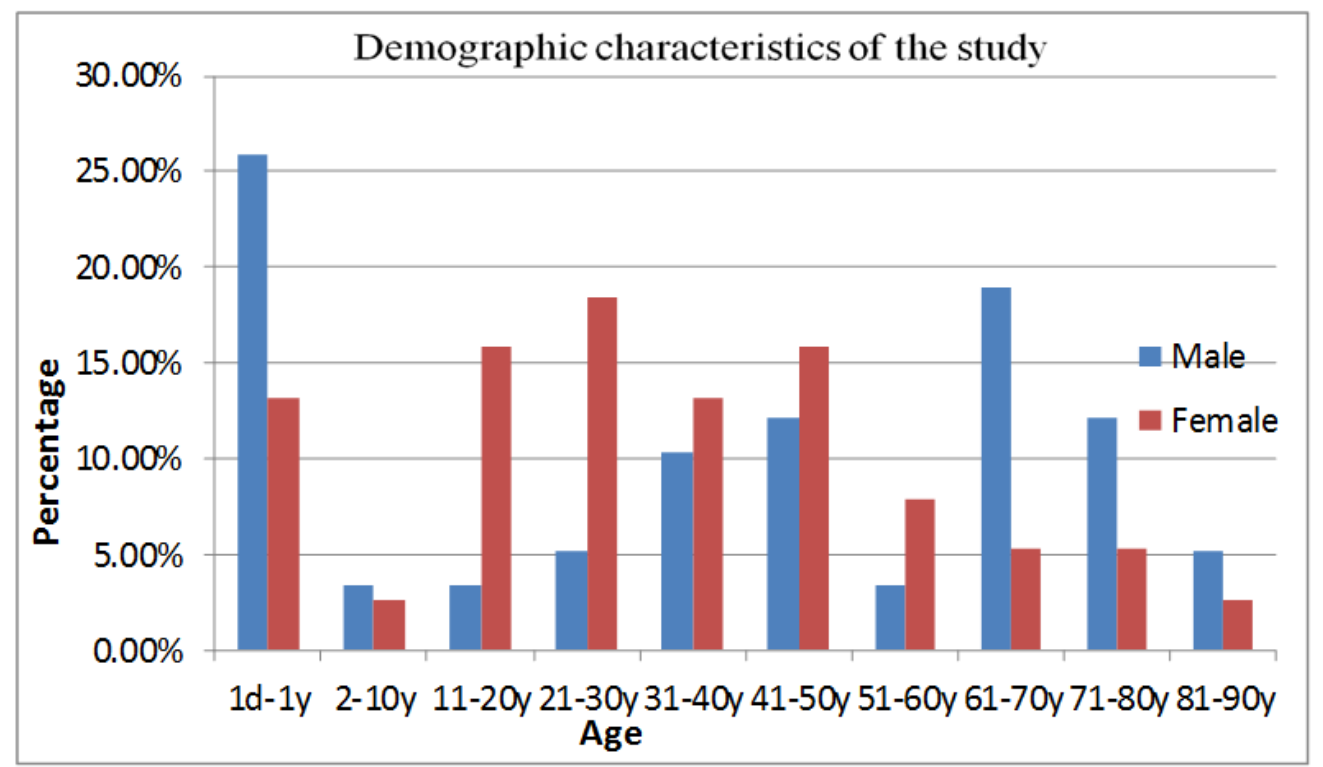


Fig.2 Distribution of nosocomial infections in ICUs

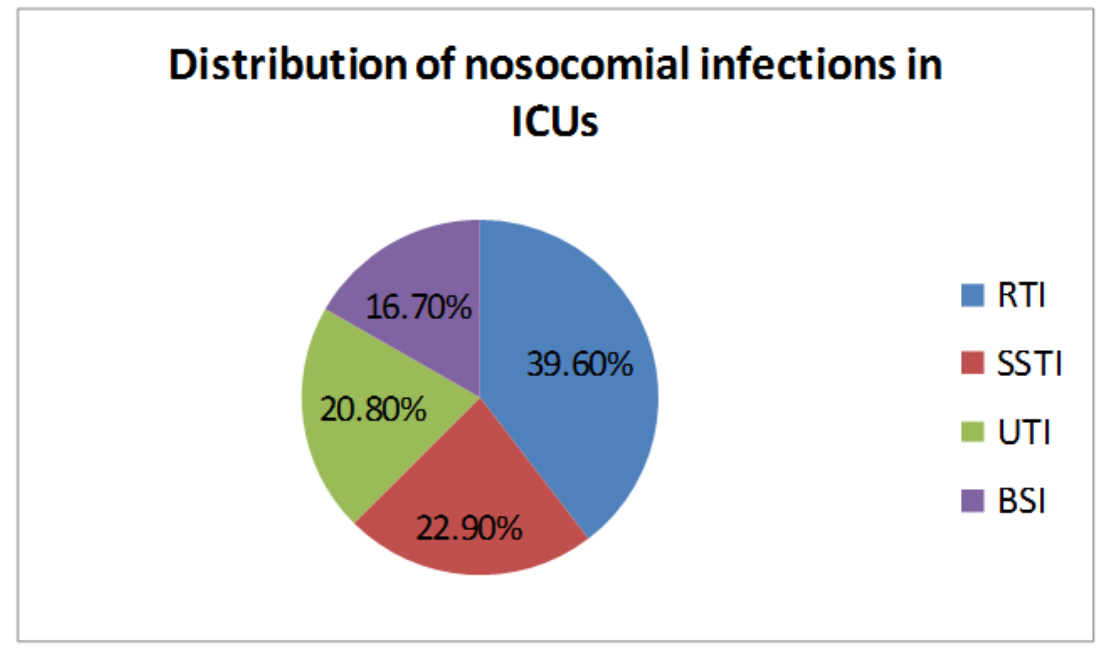

Fig.3 Antibiotic resistance pattern of Gram positive cocci

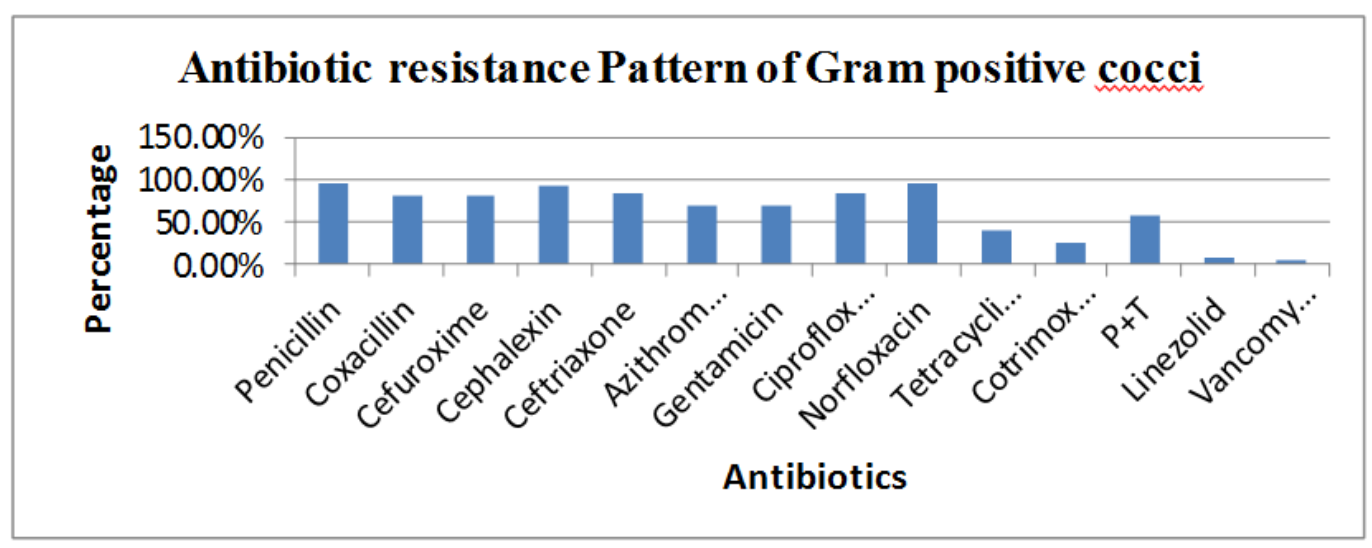

Fig.4 Percentage of nosocomial infections caused by MRSA

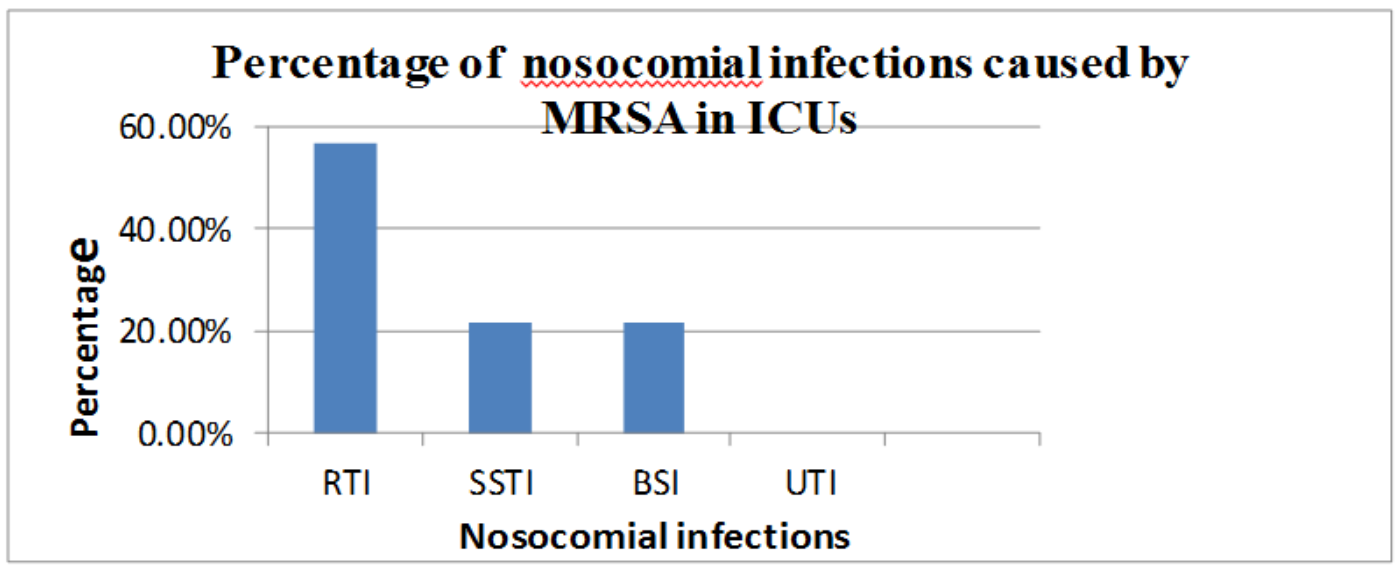


In this study a total of 202 organisms were isolated from 192 various clinical samples. Most of the isolates were from respiratory samples 76 (39.5\%) [Sputum 38 (19.8\%), endotracheal secretion $32(16.7 \%)$ and throat swab $6(3.12 \%)$ ] followed by pus samples 44 (22.9\%). Our data correlates with the results of study conducted by (Zhanel et al., 2005). Another report by (Patel BV et al., 2012) highlights the variability in distribution of specimens where most of the isolates were from urine samples followed by blood and pus. The widespread use of tracheal intubation and mechanical ventilation to support the patients in ICUs increases the risk of nosocomial respiratory tract infections.

In the present study most of the samples obtained were from males $116(60.6 \%)$ and $76(39.6 \%)$ were from females. This is in consistence with the study conducted by (Zhanel et al., 2005) where most of the isolates were from male patients. It is in contrast with the study conducted by (AlJawady et al., 2005) where most of the isolates were obtained from females. The major age group was $<1$ year which included 40 (20.9\%) samples followed by $41-50$ years and 61-70 years which included $26(13.5 \%)$ samples. It is in contrast with the study conducted by (Zhanel et al., 2005) where the major age group was 18-64 years. This is probably due to low level of immunity in $<1$ year age group and higher incidence of serious illness in ageing population.

In this study respiratory tract infection 76(39.6\%) was the most common infection. It was followed by skin and soft tissue infection $44(22.9 \%)$, urinary tract infection $40(20.8 \%)$ and blood stream infection $32(16.7 \%)$. The widespread use of mechanical ventilation and endotracheal intubation in critically ill patients increases the risk of nosocomial respiratory tract infections. Comparable results have been published by (Aksaray et al., 2000) and (Radji et al., 2011). It is in contrast with the study conducted by (Mythri et al., 2014) where the most common nosocomial infection was urinary tract infection followed by respiratory tract infection.

Out of the 192 patients suffering from nosocomial infections $82 \quad(42.7 \%)$ were suffering from comorbid conditions like hypertension, diabetes, COPD and AIDS. The presence of comorbid conditions may aggravate the underlying clinical conditions and increase the risk of complications and may also influence the treatment response or outcome. Similar comorbid conditions were seen in studies conducted by (Datta et al., 2014).

The most common Gram positive cocci was Staphylococcus aureus 34 (56.6\%) followed by Coagulase negative Staphylococci 16 (26.6\%). This is similar to the other previous studies (Radji et al., 2011; Patel et al., 2012; Mathur et al., 2005). It may be due to their wide prevalence in the hospital environment. In addition, their frequent resistance to antibiotic may play a role in their persistence and spread (Al- Jawady et al., 2012).

The most common nosocomial infection caused by Staphylococcus aureus was respiratory tract infections $16(47.1 \%)$. This data is similar to the studies conducted by (Zhanel GG et al., 2005) and (Sharma SK et al., 2013) but is in contrast with the other studies (Al- Jawady et al., 2012; Patel et al., 2012). 12 (75\%) of CONS caused blood stream infections. This data correlates with the study conducted by (Zhanel et al., 2005) but is in contrast with the study conducted by (Sharma et al., 2013). Where Enterococcus was the most common cause of blood stream infections. Bacterial polysaccharide components are involved in attachment / persistence of bacterial on foreign materials 
(indwelling devices). They can colonise the polymer surface by formation of thick multilayered biofilm and track down the catheters causing bloodstream infection. 4 (40\%) of Enterococcus species was the major cause of urinary tract infection. This is in accordance with the studies conducted by (Zhanel GG et al., 2005). The data shows variability with the study conducted by Sharma et al., (2013). 4(40\%) of Enterococcus species was the major cause and skin and soft tissue infection. This data is in contrast with other studies (Al-Jawady et al., 2012; Zhanel et al., 2005; Sharma et al., 2013) where $S$. aureus was the most common organism isolated from skin and soft tissue infection.

Staphylococcus aureus was the most common Gram positive isolate in CCU, ICCU, NICU and SICU. This is in accordance with the previous studies (Deepa et al., 2014; Tsering et al., 2011).

Antimicrobial agents are among the most commonly used drugs among hospitalised patients. The emergence of antimicrobial resistance in ICUs is of great concern as it increases the like hood of drug interactions / side effects and cost of therapy due to use of newer antibiotics. In the present study maximum resistance was seen against penicillin and norfloxacin (96.6\%) followed by cephalexin $(93.3 \%)$ and ceftriaxone, ciprofloxacin $(83.3 \%)$. This high rate of resistance might be due to the selective influence of extensive usage of these drugs. Minimum resistance was seen against vancomycin $(6.7 \%)$ followed by linezolid $(10 \%)$ and cotrimoxazole $(26.6 \%)$. The high level of sensitivity may be due to less frequent use of such antibiotics in hospital. These data are comparable with the results by (Al Jawady et al., 2012; Datta et al., 2014; Sheth et al., 2012; Zhanel et al., 2005) where minimum resistance was seen against vancomycin and linezolid and maximum resistance was seen against beta lactam group of drugs like penicillin and cephalosporins. In the present study the resistance seen against fluoroquinolones like ciprofloxacin is similar with the study conducted by (Al -Jawady et al., 2012) where it was seen to be $(71.5 \%)$ but is in contrast with the study conducted by (Sheth et al., 2012) where high sensitivity was seen $(80 \%)$.

All the strains of $S$. aureus and CONS were found to be susceptible to vancomycin and linezolid followed by cotrimoxazole and tetracycline similar to previous studies (Datta et al., 2014; Radji et al., 2011; Zhanel et al., 2005). This is in contrast with the study conducted by (Sheth et al., 2012) where there was a high resistance seen against cotrimoxazole $(75 \%)$ in S. aureus. Maximum resistance was seen against penicillin and cephalosporins followed by cloxacillin. High resistance was also seen against fluoroquinolones, azithromycin and gentamicin. It is similar to other studies (AlJawady et al., 2012; Datta et al., 2014; Radji et al., 2011; Zhanel et al., 2005).

Methicillin resistant S. aureus (MRSA) was first described in 1961, reported one year of introduction of methicillin and has emerged as one of the most important nosocomial pathogens in the last two decades. MRSA is of serious concern not due to its sole resistance to methicillin but also to many other antimicrobials that are used on regular basis in hospitals. Current therapeutic options for MRSA are limited to few expensive drugs like vancomycin, linezolid, teicoplanin, daptomycin and streptogramins (Mir et al., 2013).

In the present study out of the 34 Staphylococcus aureus isolates methicillin resistance was seen in $28(82.35 \%)$. This data is in accordance with the study conducted by 
(Klevens et al., 2007) in US where the percentage of MRSA causing nosocomial infection in intensive care unit patients was $64.4 \%$. It is in contrast with the other studies where the percentage of MRSA is comparatively lower.

This variation in percentage may be because of several factors like healthcare facilities available in the particular hospital, implementation and monitoring of infection control committee, rationale antibiotic usage which varies from hospital to hospital. In the present study high percentage of MRSA is seen because of indiscriminate use of antibiotics without drug sensitivity testing which may be due to negligence on the part of medical practitioners or patients' poor economic status (Mir et al., 2013).

In the present study $57.1 \%$ of MRSA caused respiratory tract infection. $21.4 \%$ of MRSA were responsible for blood stream infection and skin and soft tissue infection. This data correlates with the study conducted by (Shrestha et al., 2009) where majority of the MRSA were responsible for respiratory tract infections $(82.3 \%)$. There is variability in the percentage of infections in other studies (Zhanel et al., 2005; Mir et al., 2013; Madani et al., 2001).

To put into a nutshell nosocomial infections in ICUs are foremost aspect which needs to be tackled carefully and efficiently by the healthcare professional for the betterment of patients who are hospitalized. The prescribing of antibiotics in ICUs is usually empiric. Therefore the ongoing surveillance of antibiogram of bacteria is fundamental effort to monitor changes in susceptibility patterns and guide the clinician in choosing empirical therapy appropriately. Appropriate antibiotic utilization in ICUs is crucial in ensuring optimal outcome and preventing the emergence of multidrug resistance bacteria.

\section{References}

Aksaray S, Dokuzoguz B, Guvener E, Yucesoy $\mathrm{M}$, Yulug $\mathrm{N}$, Kocagoz $\mathrm{S}$ et al., Surveillance of antimicrobial resistance among Gram negative isolates from intensive care units in eight hospitals in Turkey. J Antimicrobial Chemotherapy 2000; 45:695-9.

Al -Jawady ZA, Al- Habib HM. Antibiogram Profiles of Bacterial Isolates from Intensive Care Units in Mosul Teaching Hospitals. Raf. J. Sci 2012; 23:52-9.

CDC. Identifying health care infection for NHSN surveillance. January 2016. Available

from

URL:htpp://www.cdc.gov/nhsn/

Cekovska Z, Panovski N, Petrovska M. Methicillin- resistant Staphylococcus aureus: Comparison of susceptibility test methods with mecA gene analysis for determining oxacillin (Methicillin) resistance in our clinical isolates. Bratisl Lek Listy 2005; 106:163-7.

CLSI. Performance Standards for Antimicrobial Disc Susceptibility Tests; Approved standard $11^{\text {th }}$ edition. CLSI document M02-A11. Wayne, PA: Clinical and Laboratory Standards Institute; 2012.

Collee JG, Doguid JP, Fraser AG and Marmion BP. Mackie and Mc Cartney. Practical medical microbiology: $14^{\text {th }}$ ed. Churchill Livingstone, USA: Elsevier; 1989.

Datta P, Rani H, Chauhan R, Gombar S, Chander J. Health- care- associated infections: Risk factors and epidemiology from an intensive care unit in Northern India. Indian $\mathrm{J}$ of Anaesthesia 2014; 58:30-5.

Deepa S, Abhishek MU, Venkatesha D. The air as harbinger of infections in critical care units. Medical Science 2014; 8:8-13.

Kaul S, Brahmadathan KN, Jagannati M, Sudarsanam TD, Pitchamuthu K, Abraham OC et al., One year trends in the gram-negative bacterial antibiotic susceptibility patterns in a medical 
intensive care unit in South India. Indian J Med Microbiol 2007; 25:230-5.

Klevens RM, Edward JR, Richards CL, Hortan TC, Gaynes RP, Pollock DA, et al., Estimating healthcare associated infections in US hospitals, 2002. Public Health Rep 2007; 122: 160-6.

Madani TA, Al- Abdullah NA, Al-Sanousi AA, Ghabrah TM, Afandi SZ et al., Methicillin - resistant Staphylococcus aureus in two tertiary care centres in Jeddah, Saudi Arabia. Infect Control Hosp Epidemiol 2001; 22:211-6.

Mathur P, Kapil A, Das B.Nosocomial bacteraemia in intensive care unit patients of a tertiary care centre. Indian J Med Res 2005; 122:305-8.

Mir BA, Srikanth. Prevalance and antimicrobial susceptibility of methicillin resistant Staphylococcus aureus and Coagulase Negative Staphylococci in a tertiary care hospital. Asian J Pharma Clin Res 2013; 6: 231-4.

Mythri H, Kashinath KR. Nosocomial infections in patients admitted in intensive care unit of a tertiary health center, India.Ann Med Health Sci Res 2014;4:738-41.

Patel BV, Patel PG, Raval PN, Patel MH, Patel $\mathrm{PH}$, Vegad MM. Bacteriological profile and antibiogram of Gram negative organisms isolated from neurology intensive care unit with special reference to multidrug resistant organisms. National J Med Res 2012; 2: 335-8.

Radji M, Fauziah S, Aribinuko. Antibiotic sensitivity pattern of bacterial pathogens in the intensive care unit of Fatmawati Hospital, Indonesia. Asian Pae J Trop Biomed 2011; 1: 39-42.
Robert AW. Nosocomial infection update. Emerging Infectious Diseases 1998; 4:416-20.

Sharma DK, Tiwari YK, Vyas N, Maheshwari RK. An investigation of the incidence of Nosocomial infections among the patients admitted in the intensive care unit of a tertiary care hospital in Rajasthan, India. Int J Curr Microbiol App Sci 2013; 2: 428-35.

Sharma SK, Hadda V, Mathur P, Gulati V, Sahney C. Profile of microorganisms in intensive care unit of a level -1 trauma centre: A retrospective study. Indian $\mathbf{J}$ Crit Care Med 2013; 17: 87-91.

Sheth KV, Patel TK, Malek SS, Tripathi CB. Antibiotic Sensitivity Pattern of Bacterial Isolates from the Intensive Care Unit of a Tertiary Care Hospital in India. Tropical Journal of Pharmaceutical Research 2012; 11: 991-9.

Shrestha B, Pokhrel B, Mohapatra T. Study of nosocomial isolates of Staphylococcus aureus with special reference to methicillin resistant S.aureus in a tertiary care hospital in Nepal. Nepal Med Coll J 2009; 11: 123-6.

Tsering DC, Chanchal L, Pal R, Kar S. Bacteriological Profile of Septicemia and the Risk Factors in Neonates and Infants in Sikkim. J Glob Infect Dis 2011; 3: 425.

Zhanel GG, DeCorby M, Laing N, Weshnoweski B, Vashist R, Tailor F et al., Antimicrobial resistant pathogens in Intensive Care Units in Canada: Results of the Canadian National Intensive Care Unit (CAN-ICU) study, 2005-2006. Antimicrob. Agents Chemother 2008; $52: 1430-7$

\section{How to cite this article:}

Zarrin Afroz, Basavaraj C. Metri, Faisal Nasim Gilani and Jyothi, P. 2018. Bacteriological Profile and Antibiogram of Gram Positive Nosocomial Isolates from Intensive Care Units with Special Reference to Methicillin Resistant Staphylococcus aureus (MRSA) in a Tertiary Care Hospital of North Karnataka, India. Int.J.Curr.Microbiol.App.Sci. 7(10): 3259-3269. doi: https://doi.org/10.20546/ijcmas.2018.710.377 